\title{
Diazo-based Copolymers for the Wet Strength Improvement of Paper Based on Thermally Induced CH-insertion Crosslinking - Supporting Information
}

S. Schölch ${ }^{1,2,4}$, J.-L. Schäfer ${ }^{3,4}$, T. Meckel ${ }^{3}$, T. Brandstetter ${ }^{1}$, M. Biesalski and J. Rühe ${ }^{1,2}$

${ }^{1}$ Department of Microsystems Engineering (IMTEK), Laborarory for Chemistry \& Physics of Interfaces, Albert-Ludwigs-Universität Freiburg, Georges-Köhler-Allee 103, 79110 Freiburg, Germany

${ }^{2}$ Freiburg Institute for Interactive Materials and Bioinspired Technologies (FIT), Albert-Ludwigs-Universität Freiburg, Georges-Köhler-Allee 105, 79110 Freiburg, Germany

${ }^{3}$ Makromolekulare Chemie und Papierchemie, Technische Universität Darmstadt, Alarich-Weiss-Straße 8, 64287 Darmstadt, Germany

${ }^{4}$ authors contributed equally

*correspondence: e-mail: biesalski@cellulose.tu-darmstadt.de; e-mail: ruehe@imtek.uni-freiburg.de

\section{XPS of cellulose model surface}
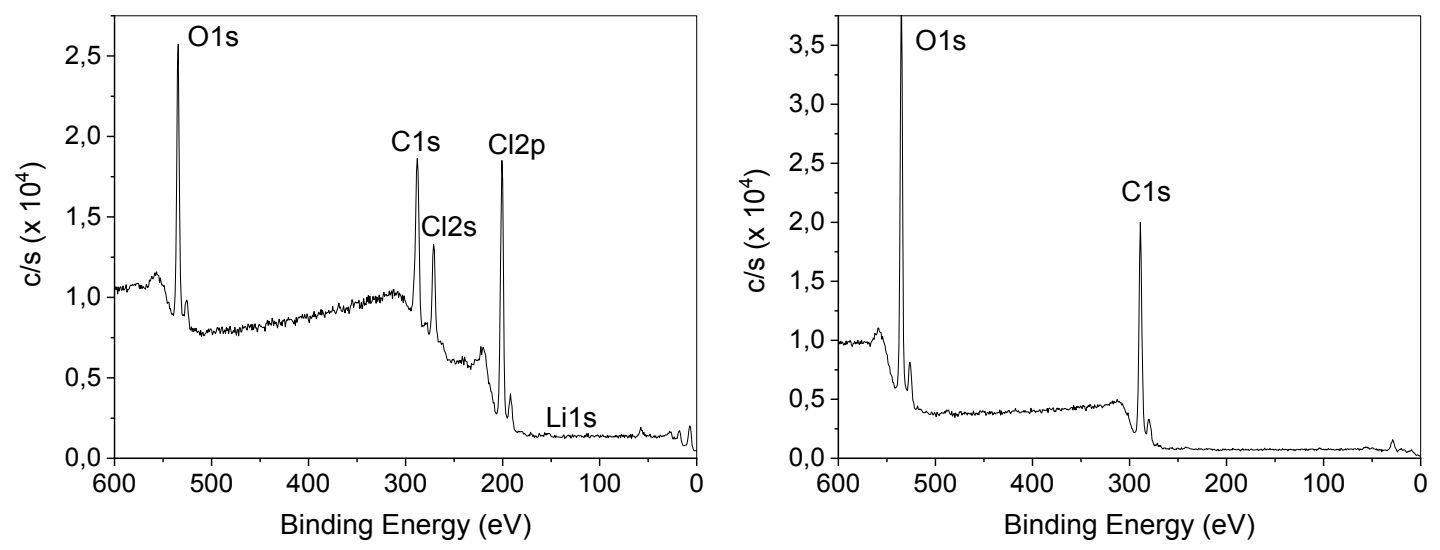

Figure 1. XPS spectra of a cellulose model surface, prepared from a solution of microcrystalline cellulose in DMAc/LiCl (1 wt\%) via spin-coating. left: before removal of $\mathrm{LiCl}$ by washing with water. right: after removal of LiCl by washing with water.

FTIR of cellulose model surface 


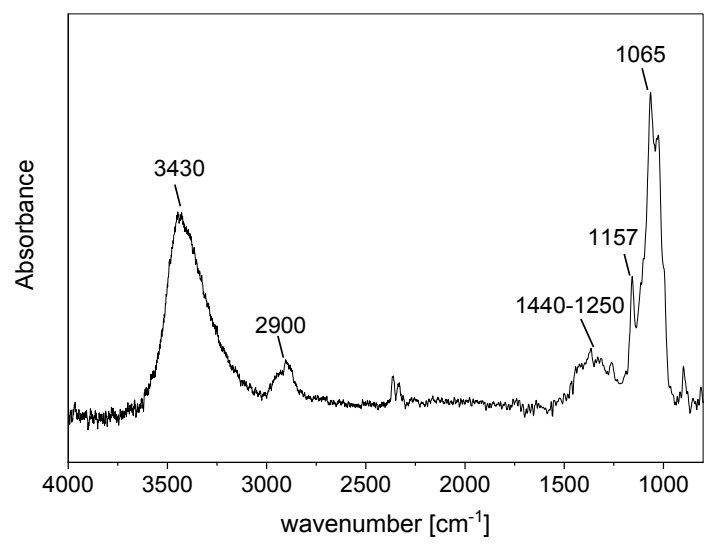

Figure 2. Infrared-spectrum of a cellulose model surface with $20 \mathrm{~nm}$ thickness, prepared from a solution of microcrystalline cellulose in $\mathrm{DMAC} / \mathrm{LiCl}(1 \mathrm{wt} \%)$ via spin-coating.

\section{AFM of cellulose model surface}
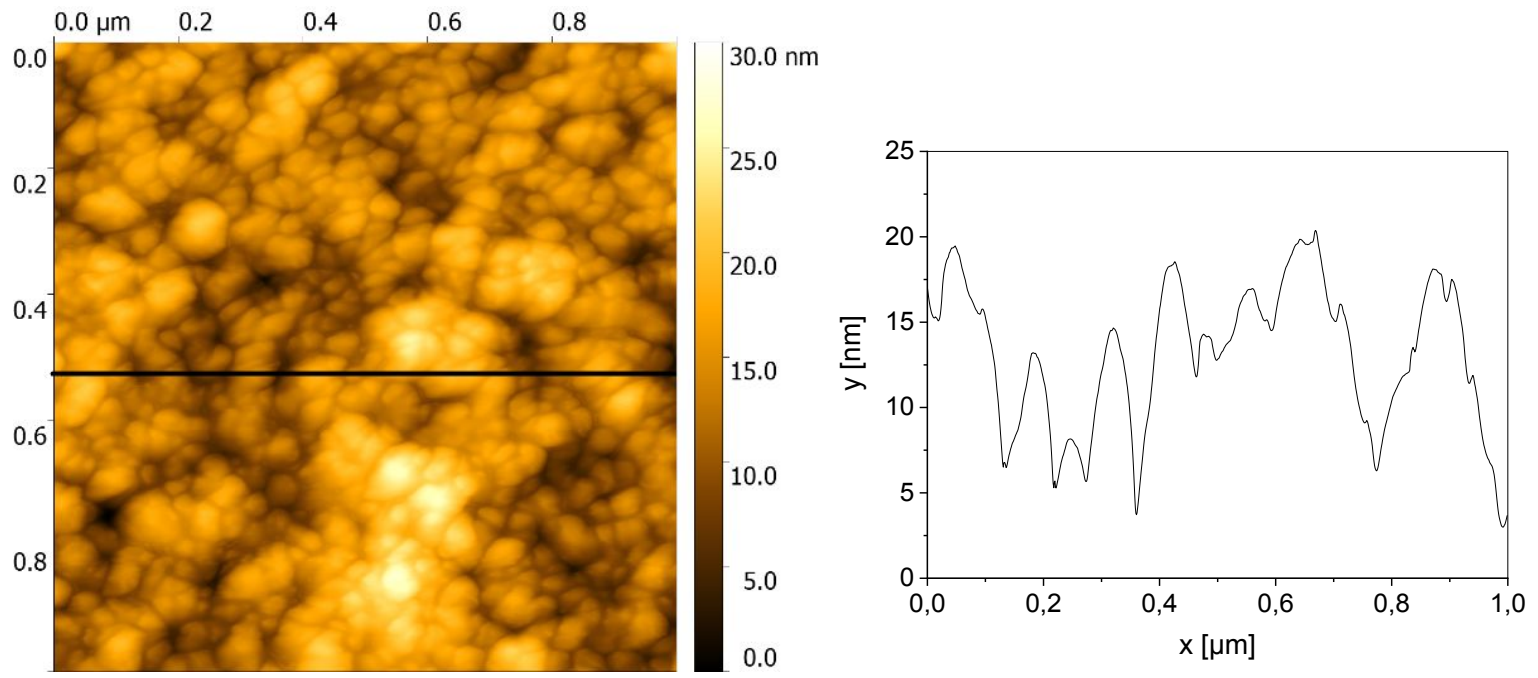

Figure 3. Left: AFM measurements of a cellulose model surface, prepared from a solution of microcrystalline cellulose in $\mathrm{DMAc} / \mathrm{LiCl}(1 \mathrm{wt} \%$ ) via spin-coating. The profile shown in the right image is measured along the black line in the left image at $0.5 \mu \mathrm{m}$. Images were acquired and evaluated as described in the experimental section.

\section{Polymer synthesis}

Table 1. List of copolymers used in this work.

Applied Copolymer components

Crosslinker-content according to ${ }^{1} \mathrm{H}-\mathrm{NMR}$
Molecular weight

$\mathrm{M}_{\mathrm{n}} / \mathrm{M}_{\mathrm{w}}\left[\mathrm{kg} \cdot \mathrm{mol}^{-1}\right]$ 


\begin{tabular}{l|c|c}
\hline p(DMAA-5\%-PEDAz-1\%-AEMA-RhoB) & $4.4 \%$ & $49 / 149$ \\
p(DMAA-5\%-MAz-1.5\%-AmS-RhoB) & $4.7 \%$ & $43 / 178$ \\
p(DMAA-3\%-PEDAz-0.25\%-RhoBMA) & $2.9 \%$ & $64 / 191$ \\
p(DMAA-3\%-MAz-0.25\%-RhoBMA) & $2.4 \%$ & $31 / 125$
\end{tabular}

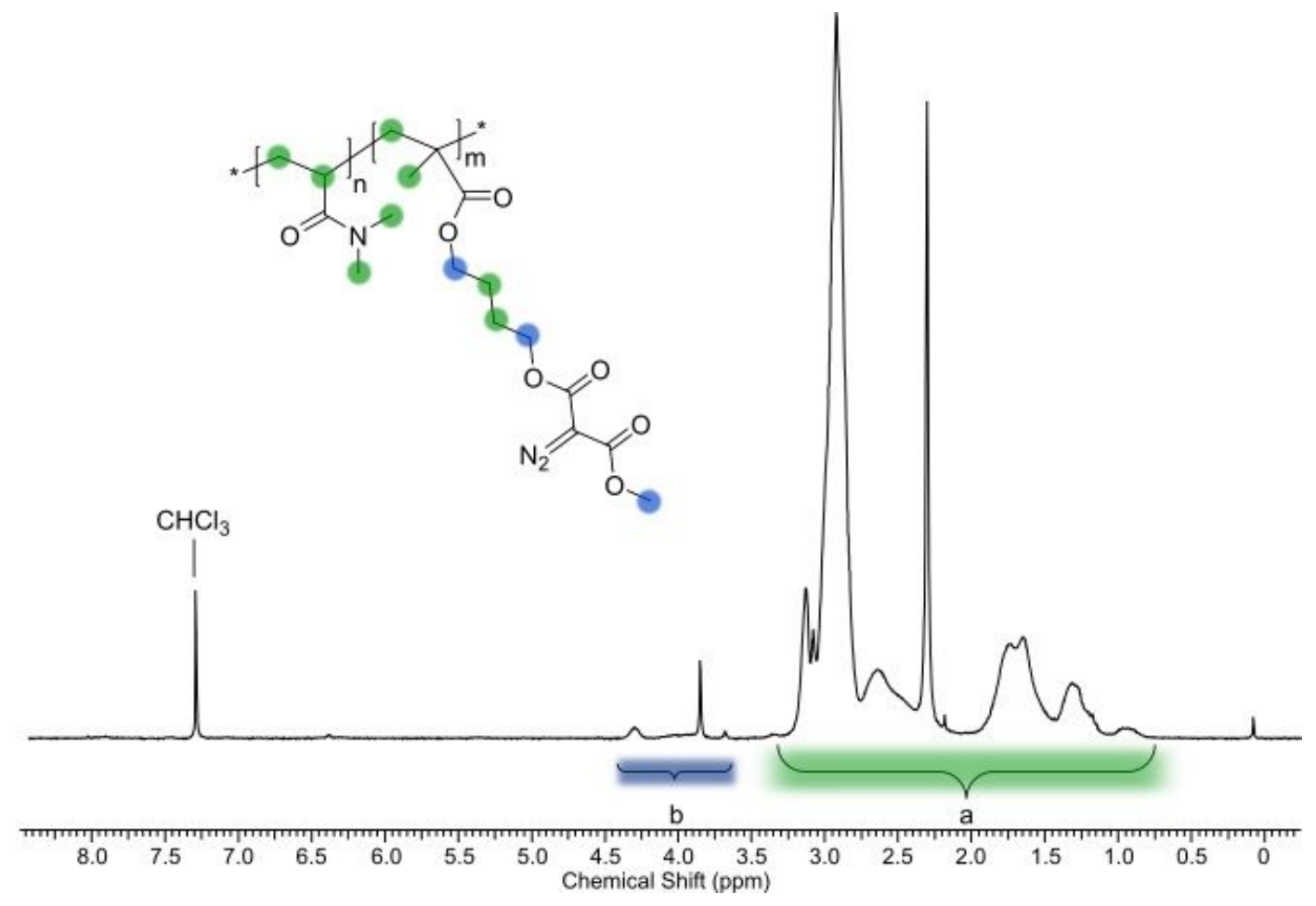

Figure 4. Representative ${ }^{1} \mathrm{H}-\mathrm{NMR}$ of $\mathrm{p}$ (DMAA-co-MAz). The crosslinker content can be calculated from the ratio of the protons in area $a$ compared to area $b$. 

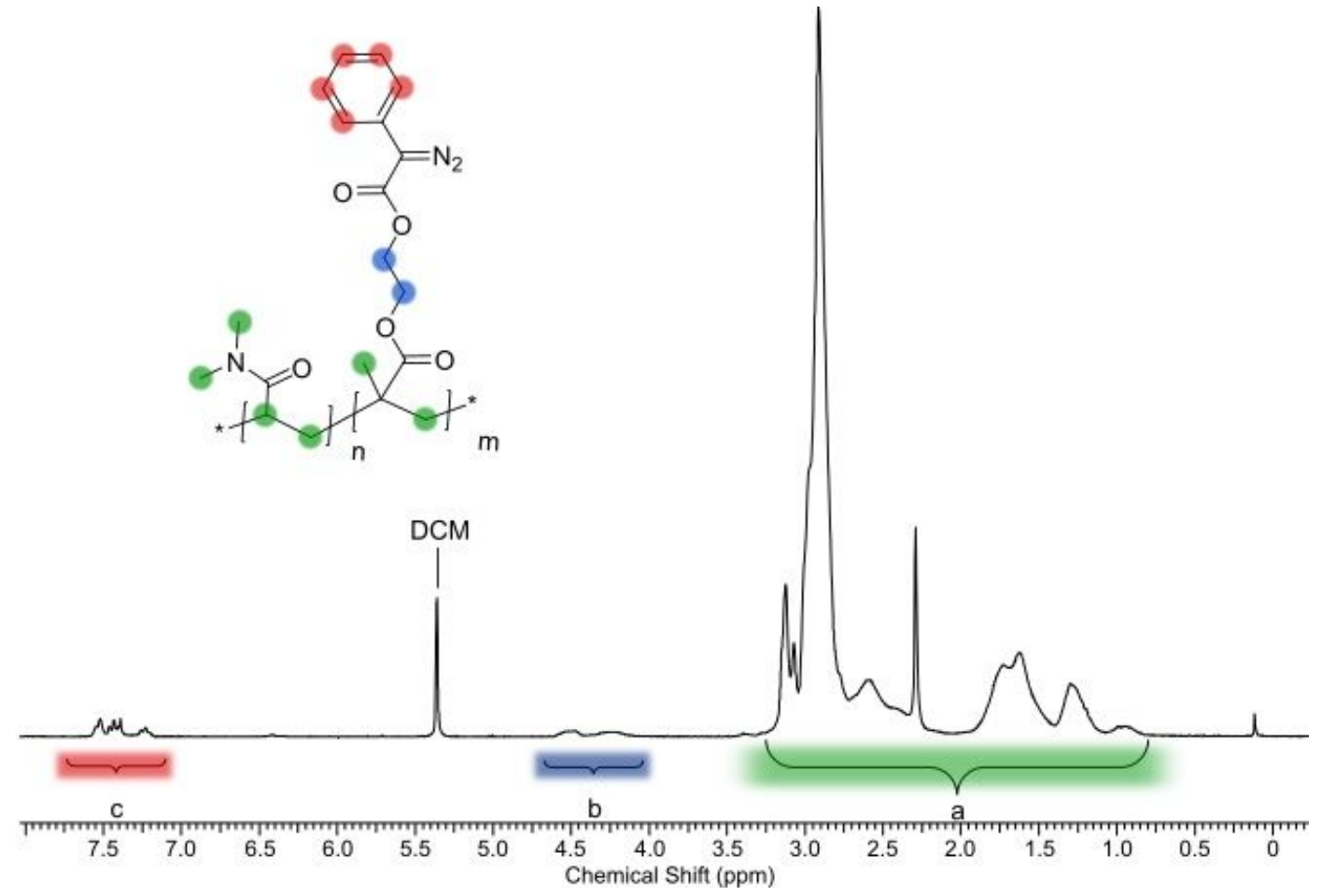

Figure 5. Representative ${ }^{1} \mathrm{H}-\mathrm{NMR}$ of $\mathrm{p}(\mathrm{DMAA}-\mathrm{Co}-\mathrm{PEDAz})$. The crosslinker content can be calculated from the ratio of the protons in area a compared to either area $b$ or area $c$.

\section{Comparison rel. fluorescence vs. gravimetric experiments}
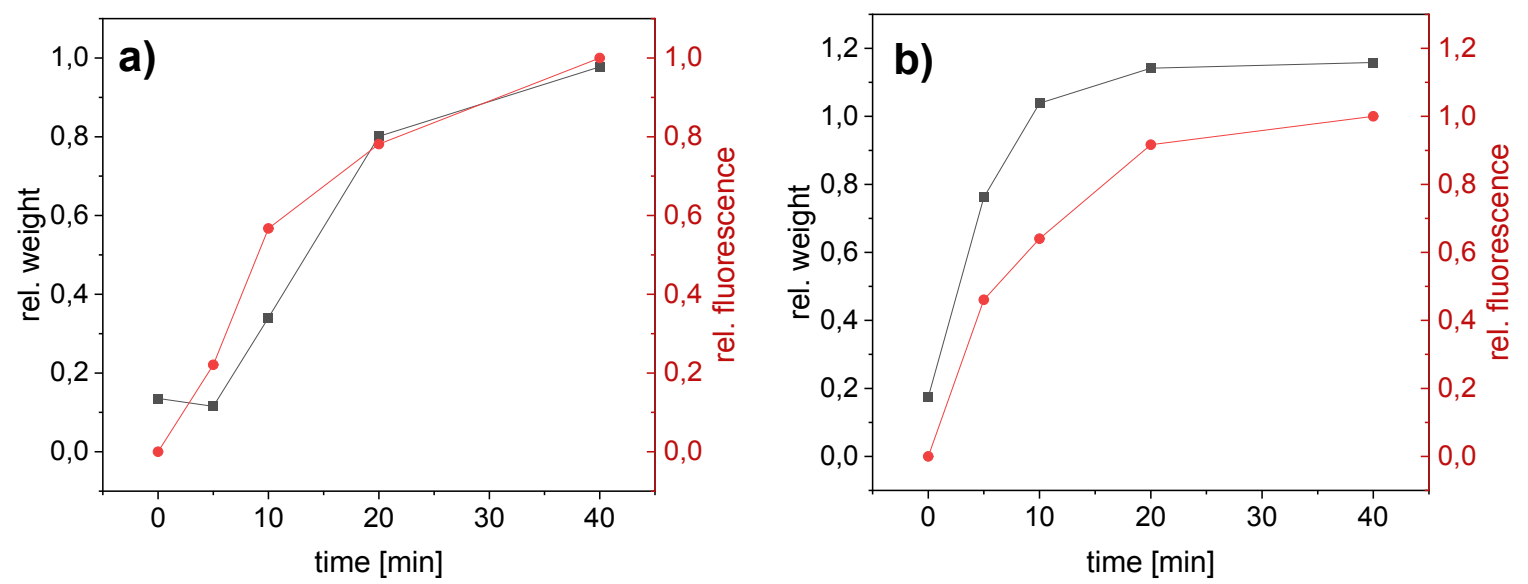

Figure 6. Comparison between the relative fluorescence (normalized) and the relative amount of polymer attached to the paper, determined gravimetrically at controlled conditions $\left(23^{\circ} \mathrm{C}, 50 \% \mathrm{RH}\right)$ before and after extraction of unbound polymer. a) p(DMAA-3\%-MAz-AEMA-RhoB) at $160^{\circ} \mathrm{C}$ and b) p(DMAA-3\%-PEDAz-AEMA-RhoB) at $130^{\circ} \mathrm{C}$. 


\section{Tensile measurements}

Table 2. Gravimetric data for the modification of eucalyptus sulfate paper (grammage $=80 \mathrm{~g} \cdot \mathrm{m}^{-2}$ ) with two different DMAA-copolymers. Crosslinking was performed thermally. Given values are averages of 10 samples.

\begin{tabular}{c|c|c|c|c} 
Copolymer & Crosslinking & $\mathrm{m}(\mathrm{CoPo})$ & $\mathrm{m}(\mathrm{CoPo})$ & wt.-\% \\
& conditions & after soaking $[\mathrm{mg}]$ & $\begin{array}{c}\text { after extraction } \\
{[\mathrm{mg}]}\end{array}$ & $\begin{array}{c}\text { CoPo / total } \\
\text { paper weight }\end{array}$ \\
\hline p(DMAA-3\%-MAz) & $160^{\circ} \mathrm{C}, 40 \mathrm{~min}$ & 21.5 & $19.1(89 \%)$ & 11.7 \\
p(DMAA-3\%-PEDAz) & $130^{\circ} \mathrm{C}, 40 \mathrm{~min}$ & 21.5 & $19.5(91 \%)$ & 11.9
\end{tabular}

Table 3. Dry tensile measurements of copolymer-modified eucalyptus sulfate paper.

\begin{tabular}{|c|c|c|c|c|c|}
\hline Copolymer & $\begin{array}{c}\text { Grammage } \\
{\left[\mathrm{g} \cdot \mathrm{m}^{-2}\right]}\end{array}$ & $\begin{array}{c}\mathrm{S}_{\mathrm{dry}} \\
{\left[\mathrm{kN} \mathrm{m}^{-1}\right]}\end{array}$ & $\begin{array}{l}\text { Error } S_{d r y} \\
{\left[\mathrm{kN} \mathrm{m}^{-1}\right]}\end{array}$ & $\begin{array}{c}\mathrm{I}_{\mathrm{dry}} \\
{\left[\mathrm{N} \mathrm{m} \mathrm{g}^{-1}\right]}\end{array}$ & $\begin{array}{l}\text { Error }_{\mathrm{dry}} \\
{\left[\mathrm{N} \mathrm{m} \mathrm{g}^{-1}\right]}\end{array}$ \\
\hline p(DMAA-3\%-MAz) & 80 & 1.6539 & 0.1485 & 20.6733 & 1.8568 \\
\hline p(DMAA-3\%-PEDAz) & 80 & 3.2392 & 0.2437 & 40.4902 & 3.0466 \\
\hline
\end{tabular}

Table 4. Wet tensile measurements of copolymer-modified eucalyptus sulfate paper.

\begin{tabular}{c|c|c|c|c|c} 
Copolymer & Grammage & $\mathrm{S}_{\text {wet }}$ & Error $\mathrm{S}_{\text {wet }}$ & $\mathrm{I}_{\text {wet }}$ & Error $\mathrm{I}_{\text {wet }}$ \\
& {$\left[\mathrm{g} \cdot \mathrm{m}^{-2}\right]$} & {$\left[\mathrm{kN} \mathrm{m}^{-1}\right]$} & {$\left[\mathrm{kN} \mathrm{m}^{-1}\right]$} & {$\left[\mathrm{N} \mathrm{m} \mathrm{g}^{-1}\right]$} & {$\left[\mathrm{N} \mathrm{m} \mathrm{g}^{-1}\right]$} \\
\hline $\mathrm{p}$ (DMAA-3\%-MAz) & 80 & 0.5658 & 0.04589 & 7.0724 & 0.5736 \\
$\mathrm{p}$ (DMAA-3\%-PEDAz) & 80 & 0.9348 & 0.0442 & 11.6855 & 0.5535
\end{tabular}



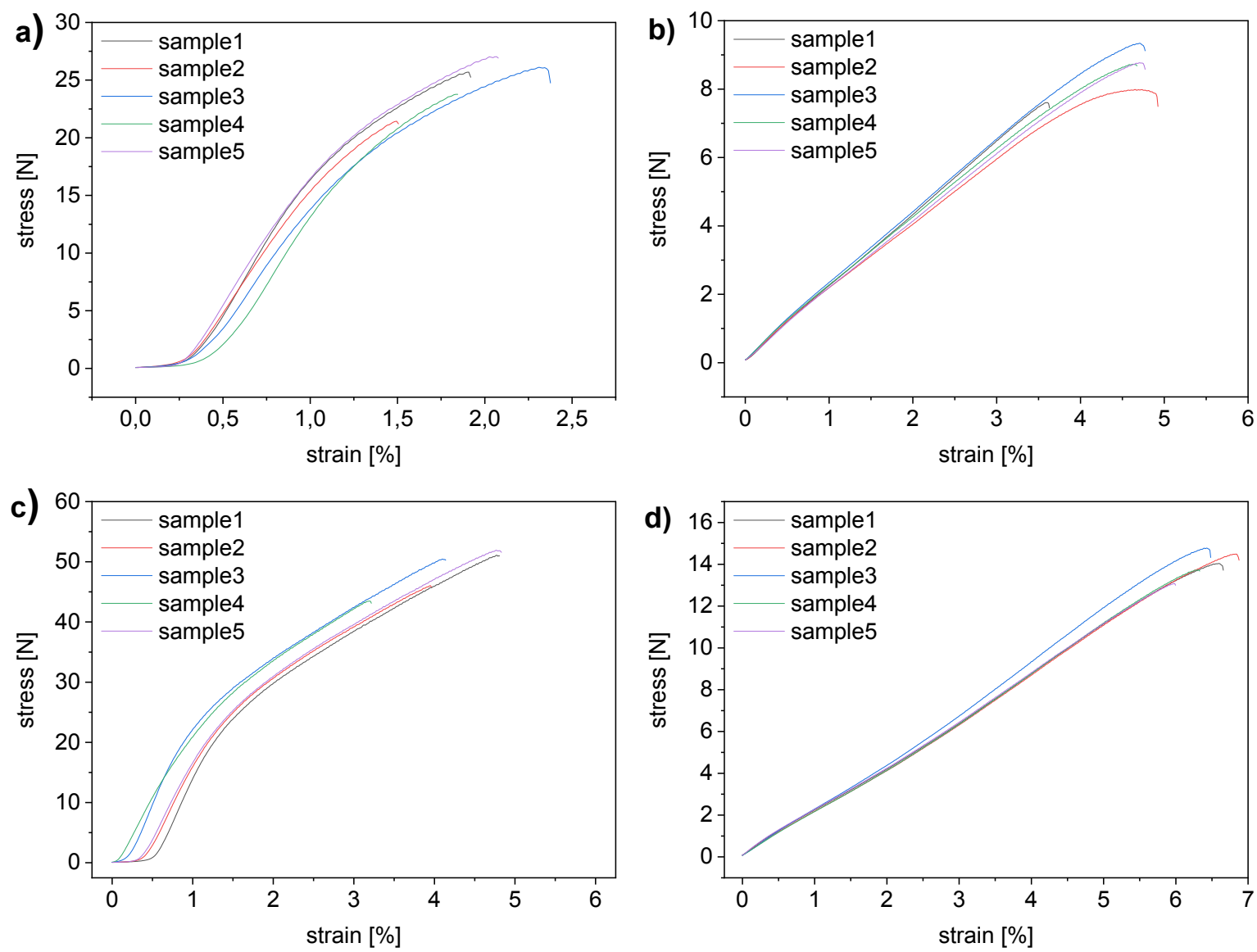

Figure 7. Stress-strain curves measured for polymer-modified eucalyptus paper (grammage $=80 \mathrm{~g} \cdot \mathrm{m}^{-2}$ ). Dry $(\mathrm{a})$ and wet (b) tensile testing for the modification with $\mathrm{p}(\mathrm{DMAA}-3 \%-\mathrm{MAz})$ at $160^{\circ} \mathrm{C}$ for $40 \mathrm{~min}$. Dry (c) and wet (d) tensile testing for the modification with $\mathrm{p}(\mathrm{DMAA}-3 \%-\mathrm{PEDAz})$ at $130^{\circ} \mathrm{C}$ for $40 \mathrm{~min}$. 